\title{
Web-Based Survey for Consumers
}

\author{
M Iffan ${ }^{1 *}$, N Shafira ${ }^{2}$ \\ ${ }^{1}$ Departemen Manajemen, Universitas Komputer Indonesia, Indonesia \\ 2Departemen Sastra Inggris, Universitas Komputer Indonesia, Indonesia \\ Email: *m.iffan@email.unikom.ac.id
}

\begin{abstract}
The purpose of this study is to describe the advantages of Web-based survey for Users as Consumers. The method used in this study was a qualitative method in which the data presented are data from phenomena. The results of this study proved that Web-based survey had advantages to the users as consumers viewed through how the survey team gave rewards to users after finishing surveys, the features of the web and users would help the companies by their surveys. The conclusion obtained in this study is relationships between other companies, survey teams and users as consumers have benefit to each other.
\end{abstract}

\section{Introduction}

Increasing Internet use in Indonesia offers business opportunities for the markets. When marketers know the factors affecting the actions of customers and the relationships between the factors and the type of customers, they can further improve their marketing strategies to turn potential customers into active customers while maintaining existent customers [1]. To find out these factors and the type of customers, some companies may need to see market situation in that time. Marketers need to consider how customers make choices on the Internet, choose products, and negotiate with Internet providers. This special issue aims to develop new insights, models and hypotheses about the actions of Internet customers [2]. One way to know the marketing situation is using a survey. The Internet can be an excellent medium for many survey research applications since people are connected to computer such as using Internet. Networks are seen as an effective way of collecting survey data [2]. Surveys can be obtained in two different ways electronically: via e-mail or web pages.

Web-based survey systems can generally manage and process large numbers of surveys at significantly lower costs than traditional survey modes [3]. This survey method is increasingly becoming popular because people access Internet nowadays. The Net Generation needs access to the Internet at anytime and anywhere, in addition, to use the Internet for knowledge searches, interaction and function [4]. Therefore, there is an opportunity for people using the Internet to search for goods or services details that they want. They will choose goods according to their preferences. As well as surveys, people will help companies to display the current market situation such as the most wanted products or services. Furthermore, the 


\section{International Journal of Research and Applied Technology}

$1(2)(2021) 271-277$

Journal homepage: https://ojs.unikom.ac.id/index.php/injuratech

Internet is an interactive data collection mode that allows respondents to choose the appropriate time to complete the questionnaire and make surveys more enjoyable [5].

To attract people taking surveys, survey provider will use some strategies and they are designed as attractive as possible. Different ways are available for conducting web-based surveys: via commercial platforms which are cheaper, no development needed, but missing some features; or custom-built platforms which the configure ration and creation are required but only used for one survey [5]. These have many advantages, such as the ability to manage numerous surveys, submit e-mail information, use points, and put forward a variety of questions. Through this concept, in web-based surveys, a questionnaire can be completed at anytime and anywhere. To engage and keep the respondent engaged in the surveys, it is necessary to model attractive web surveys [6]. This allows new materials to be included as more inspiring templates and vibrant images direct respondents to complete the survey in its entirety. Therefore, web-based survey methods provide a comprehensive solution. Their potential benefits include reduced costs of time and money $[7,8]$, responses quicker than traditional methods of data collection [9], more interactive or customized formats and less effort to complete and return the survey [10]. More complexity can also be applied in a web survey to simplify the collection and reporting of data and to obtain larger samples [11]. The purpose of this study is to describe the advantages of Web-based survey for Users as Consumers. The method used in this study was a qualitative method in which the data presented are data from phenomena.

\section{Method}

The writer used qualitative methods because this study aimed to analyze and describe data from the web-based survey. Qualitative method is a method in which data is written or oral and then analyzed descriptively. Qualitative research was carried out by describing the phenomena contained in the data, then proceed with the conclusions. The writer would like describe the advantages of web-based survey for Users as Consumers on nusaresearch.net website.

\section{Results and Discussion}

\subsection{Relationship between Companies, Survey team, and Users as Customers}

In Figure 1, three of them did the cooperation in order to make the cycle goes properly. If one of them did not go properly, it could be harmful to each other. The circumstance could be started from the companies or the survey team [3]. Figure 1 below shows the illustration of cooperation between companies, survey team and users. 


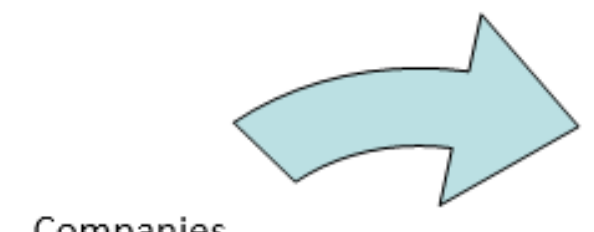

Companies

Survey

Team

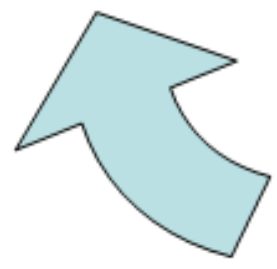

Users

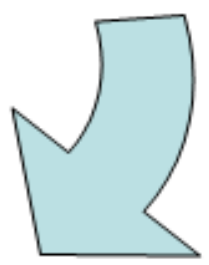

Figure 1. The illustration of cooperation between Companies, Survey team and Users as Customers.

First, if the cycle started from companies, the companies usually would request to survey team about current marketing situation. Companies needed to adjust themselves with the internal and external situation in order to satisfy customer needs. Therefore, companies would need a service from survey team to find out the situation in that time. Sometimes, the companies connected the survey with their goods or services that they have so they can predict whether the goods or services are suitable for community. Then the survey team would support the companies after they submitted their surveys and targets. Survey team became the media to spread the surveys. To find the targets for the surveys, the survey team would send notification through email so users might not miss it. The survey team also gave rewards to users who had finished the survey if it matched the target. Therefore, the level of loyalty between the survey team and the users would increase. The number of users would increase because of that benefit. After that, users as customers would take the surveys given from survey team. Normally, the surveys had a qualification so users could fill personal data to enter the surveys. If the users were qualified, the main surveys would appear, and users could finish the survey. However, if they were not qualified, they could not continue to participate in the surveys and did not receive rewards. Next, after the users had finished the surveys, the data obtained would be collected until the targets were reached. In the end, companies would get insights about marketing situation after getting the data in statistic or description.

If the cycle started from survey team, they usually would upload some popular keywords now, for example, a hand phone, brand A, or a comparison between online taxi brands. In that time, there was no agreement between survey team and companies. It means that it did not attached. Users would take the surveys as usual and finish it if they were qualified. After the data from users were collected, the survey team would show the result of surveys so the companies could use it as their data to conduct situation analysis.

\subsection{The Features on Nusaresearch.net}

To attract users to take surveys, the surveys team prepared several strategies. Figure 2 below shows login interface on nusaresearch.net. If users wanted to take surveys, they needed an account. Accounts could be used for recording the survey that you had 


\section{International Journal of Research and Applied Technology}

1(2)(2021) 271-277

Journal homepage: https://ojs.unikom.ac.id/index.php/injuratech

completed and accommodating the points that had been obtained. In order to make it easier, the users could choose some options as their Nusa Research accounts. The users could log in through social media account such as Facebook, Twitter, Google or Line. If they chose that, they only needed to confirm the authorization on the selected platform. Then, the account could be used for taking the surveys. If the users did not want to choose logging in through Facebook, Twitter, Google or Line, the users might register with their emails.

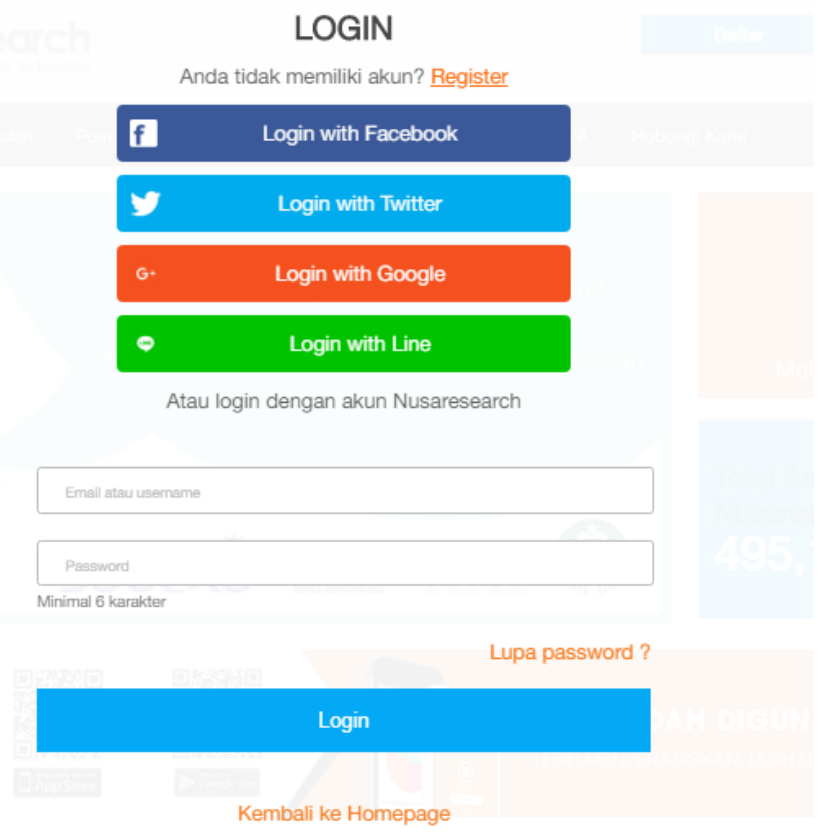

Figure 2. Login Interface on nusaresearch.net.

Then, the survey team sent them a verification mail. This feature gave benefit to log in easier and faster. It could also be an alternative to use social media account if users did not have accounts at first. Figure 3 below shows list of surveys. There were some surveys that users could take. The left one was the list from some companies and the right one as the list from fellow users. The users would get points from the left list if they were qualified to finish surveys and the result would be sent to companies. The right one was Survey Cepat. Users could take Survey Cepat or make one for their own to help fellow users if they needed a survey and it could only be used for personal. For Survey Cepat, only the quickest ones would get the reward. 


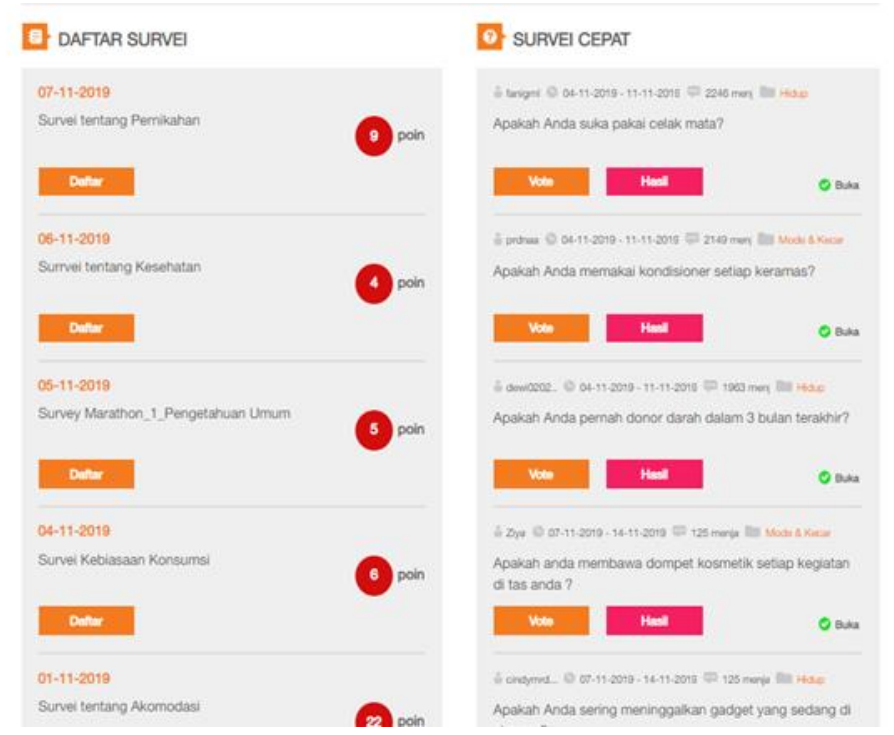

Figure 3. List of Surveys.

To make a survey in Survey Cepat, users could click Hasil Survey Cepat from Daftar Survey button and type what surveys they needed. This feature was advantageous if they wanted to know the situation in that time or thoughts on something. The users could only put two to four in this survey and it was limited for personal use only. Figure 4 below shows how to create users' own surveys.

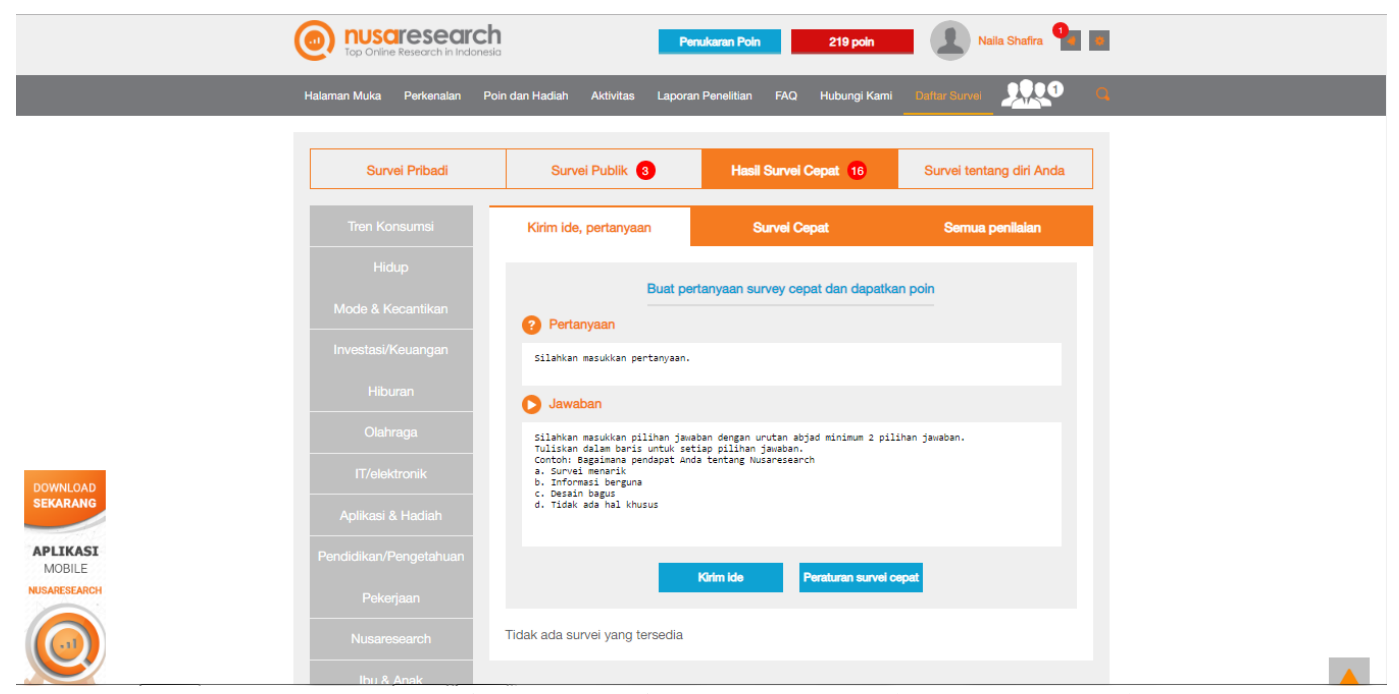

Figure 4. making users' own surveys (Survey Cepat).

3.3 Getting Rewards after finishing surveys

After users got some points and wanted to exchange of points for money, the users could choose Penukaran Poin button. The users had to confirm users account such as typing the password and birth date. The purpose of re-confirming accounts was for the safety, so the account was possibly secured. Figure 5 below shows re-confirming users' accounts page. 
International Journal of Research and Applied Technology

1(2)(2021) $271-277$

Journal homepage: https://ojs.unikom.ac.id/index.php/injuratech

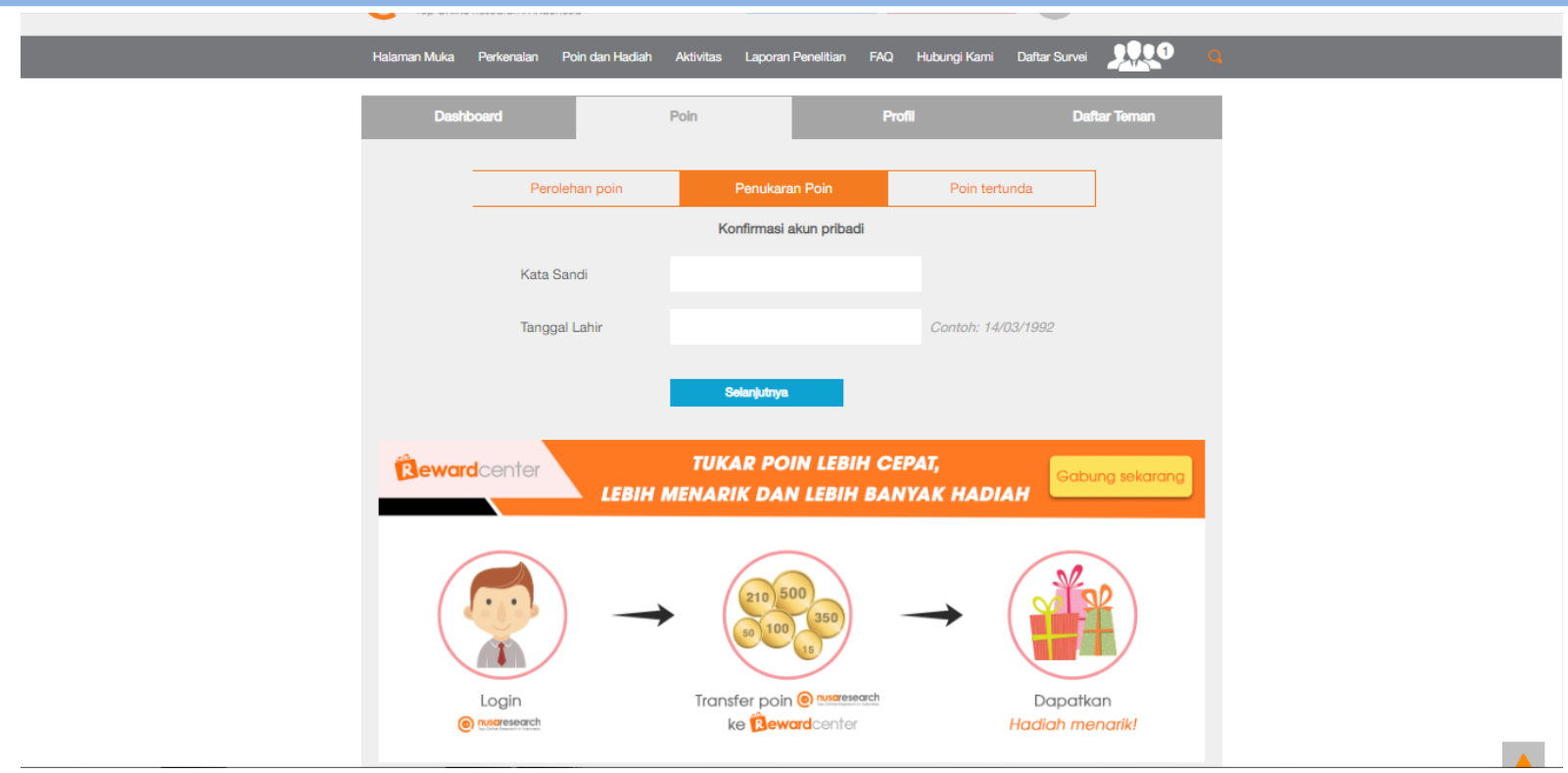

Figure 5. re-confirming users' accounts.

Figure 6 below shows rewards selection after collecting points
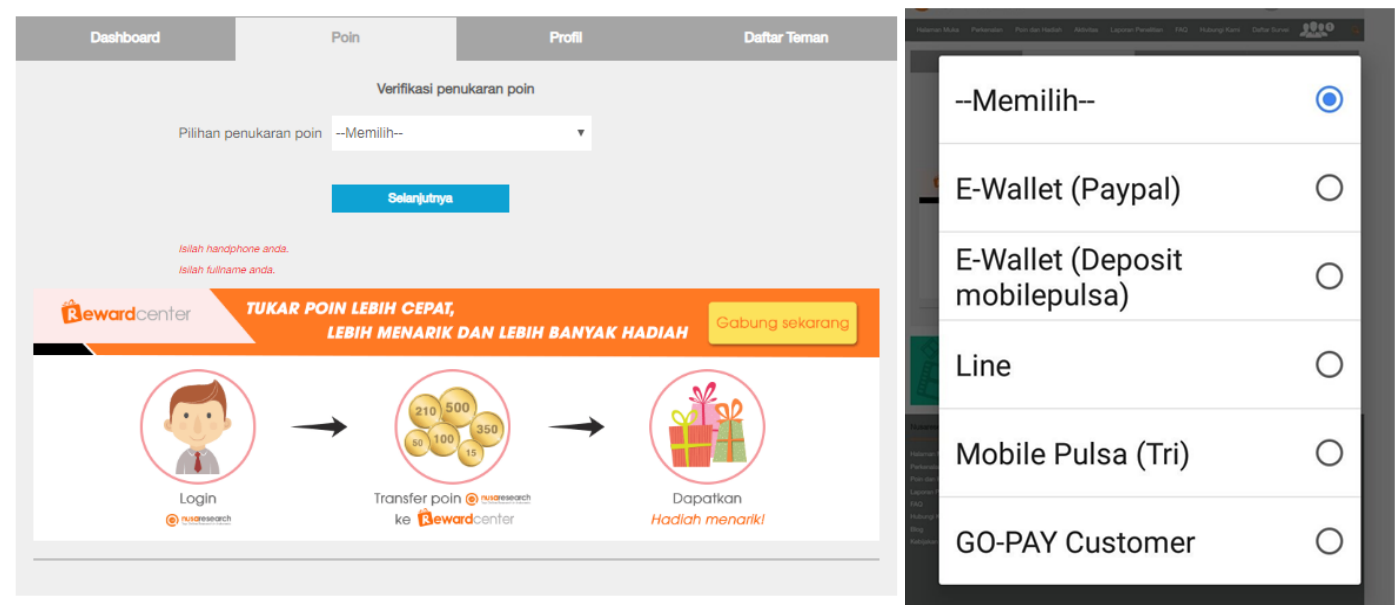

Figure 6. the Rewards selection after collecting Points.

After the users typed the password and birth date, the users could see the options of the reward payment. It could be e-wallet (PayPal, Mobile Credit deposit, or GO-PAY), Mobile Credit, or Line points. The nominal depended on the option. For example, if the users chose GO-PAY, the options would be IDR 25,000 for 500 points, IDR 50,000 for 1000 points and IDR 100,000 for 2000 points. If the users choose PayPal, the option will be $\$ 2$ for 700 points, $\$ 4$ for 1300 points and $\$ 8$ for 2500 points. Therefore, the exchange of points was different according to the option and the nominal. 


\section{International Journal of Research and Applied Technology}

1(2)(2021) 271-277

Journal homepage: https://ojs.unikom.ac.id/index.php/injuratech

\section{Conclusion}

In this paper, it presents that web-based survey can give some advantages for users as consumers. Web-based survey let the users earn extra money after finishing the survey. Furthermore, this web-based survey can be used for sharing with fellow users. Moreover, the relationship between companies, survey team, and users as costumers is significant because they help to each other. If one of them is missing, it will ruin the cycle.

\section{References}

[1] Hasan, B. 2016. Perceived irritation in online shopping: The impact of website design characteristics. Computers in Human Behavior, 54, 224-230.

[2] Yurova, Y., Rippé, C. B., Weisfeld-Spolter, S., Sussan, F., \& Arndt, A. 2017. Not all adaptive selling to omni-consumers is influential: The moderating effect of product type. Journal of Retailing and Consumer Services, 34, 271-277.

[3] Ostrow, L., Penney, D., Stuart, E., \& Leaf, P. J. 2017. Web-based survey data collection with peer support and advocacy organizations: Implications of participatory methods. Progress in community health partnerships: research, education, and action, 11(1), 4552.

[4] Maloshonok, N., \& Terentev, E. 2016. The impact of visual design and response formats on data quality in a web survey of MOOC students. Computers in Human Behavior, $62,506-515$.

[5] Monzon, A \& Bayart, C. 2018 Workshop Synthesis: Web-based surveys, new insight to address main challenges. Transportation Research Procedia, 32, pp. 167-173

[6] Greaves, S., Ellison, A., Ellison, R., Rance, D., Standen, C., Rissel, C., Crane, M., 2015. A Web-Based Diary and Companion Smartphone app for Travel/Activity Surveys. Transportation Research Procedia, 11, pp. 297-310

[7] Keramitsoglou, K. M., Manfreda, K. L., Anastasiou, C., Skjak, K. K., \& Tsagarakis, K. P. 2018. Mode comparison study on willingness to buy and willingness to pay for organic foods: paper-and-pencil versus computerized questionnaire. Electronic Commerce Research, 18(3), 587-603.

[8] Garaizar, P., \& Reips, U. D. 2019. Best practices: Two Web-browser-based methods for stimulus presentation in behavioral experiments with high-resolution timing requirements. Behavior research methods, 51(3), 1441-1453.

[9] Ohme, J., Albaek, E., \& H. de Vreese, C. 2016. Exposure research going mobile: A smartphone-based measurement of media exposure to political information in a convergent media environment. Communication Methods and Measures, 10(2-3), 135148.

[10] Klingwort, J., Buelens, B., \& Schnell, R. 2018. Early versus late respondents in web surveys: Evidence from a national health survey. Statistical Journal of the IAOS, (Preprint), 111.

[11] Lowry, P. B., D’Arcy, J., Hammer, B., \& Moody, G. D. 2016. “Cargo Cult" science in traditional organization and information systems survey research: A case for using nontraditional methods of data collection, including Mechanical Turk and online panels. The Journal of Strategic Information Systems, 25(3), 232-240. 